\title{
CASE REPORT OF LUMBOSACRAL TRANSITIONAL VERTEBRA (BERTOLOTTI'S SYNDROME)
}

Tadikonda Bhavani Prasad¹, Sameer Chaitanya Sahini², Tadikonda Krishna Srivathsav

1Professor, Department of Orthopaedics, Andhra Medical College, Visakhapatnam, Andhra Pradesh, India. 2MBBS-MS, Department of Orthopaedics, Andhra Medical College, Visakhapatnam, Andhra Pradesh, India. ${ }_{3}^{3}$ Medical Student, Department of Orthopaedics, Andhra Medical College, Visakhapatnam, Andhra Pradesh, India.

HOW TO CITE THIS ARTICLE: Prasad TB, Sahini SC, Srivathsav TK. Case report of lumbosacral transitional vertebra (Bertolotti's syndrome). J. Evolution Med. Dent. Sci. 2019;8(19):1595-1597, DOI: 10.14260/jemds/2019/353

\section{PRESENTATION OF CASE}

Lumbosacral transitional vertebra is an anatomical variation of the fifth lumbar vertebra. Transverse process becomes enlarged and forms a joint or fusion with the sacrum or ilium. In young people with low backache, one must consider it as a differential diagnosis. We report two cases with lower back pain and sciatica.

One case is of a 24-years-old girl who presented with a history of low back pain for a period of 18 months. Pain radiated to the left leg. She didn't have any co-morbidities. She took non-steroidal anti-inflammatory drugs for 12 months, but pain was not relieved. The second case is of a 26years-old girl who presented with a history of lower backache for a period of 14 months. Back pain is radiating to right leg. She didn't have any co-morbidities. She had taken non-steroidal anti-inflammatory drugs for 12 months and local steroid one time but pain still persistent. It is not a rare anatomical variation. Incidence of Bertolotti's syndrome is $4 \%$ to $21 \% 2$, 3 . Recently a very high incidence of $30 \%$ has also been reported ${ }^{3}$. Some authors opine that the transitional vertebrae cause symptoms of back pain or sciatica, some authors claim that this doesn't affect their incidence. 4,5

\section{Case Report 1}

Physical examination revealed an antalgic gait and tenderness at the lower lumbar region and left posterior iliac and sacral region. Lasegue's sign/ Bragard's sign is positive on left side. There were no motor and sensory deficits. Reflexes were normal, Babinski's sign was equivocal. There was no distal vascular deficit.

Plain x-ray and MRI done. Plain x-ray shows pseudo articulation of left L5 transverse process and the sacrum (Figure 1). MRI scan shows degeneration of disc at L4-L5 level with no stenosis.

'Financial or Other Competing Interest': None.

Submission 05-03-2019, Peer Review 30-04-2019,

Acceptance 06-05-2019, Published 13-05-2019.

Corresponding Author:

Dr. Sameer Chaitanya Sahini,

D. No. 43-3-15/1, Flat No. 203,

Ayyankala Palace, Railway New Colony,

Vishakhapatnam-530016, Andhra Pradesh, India.

E-mail: sameerchaitanyasahini@gmail.com

DOI: $10.14260 /$ jemds $/ 2019 / 353$

\section{(c) (i) (3) $\ominus$}
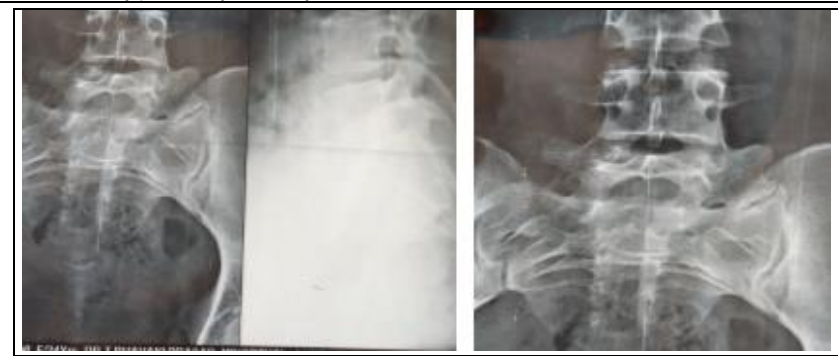

Figure 1(a). Pre-Operative X-Ray L-S Spine Anteroposterior (AP) View Shows Pseudo-Articulation of L5 with Sacrum on Left Side
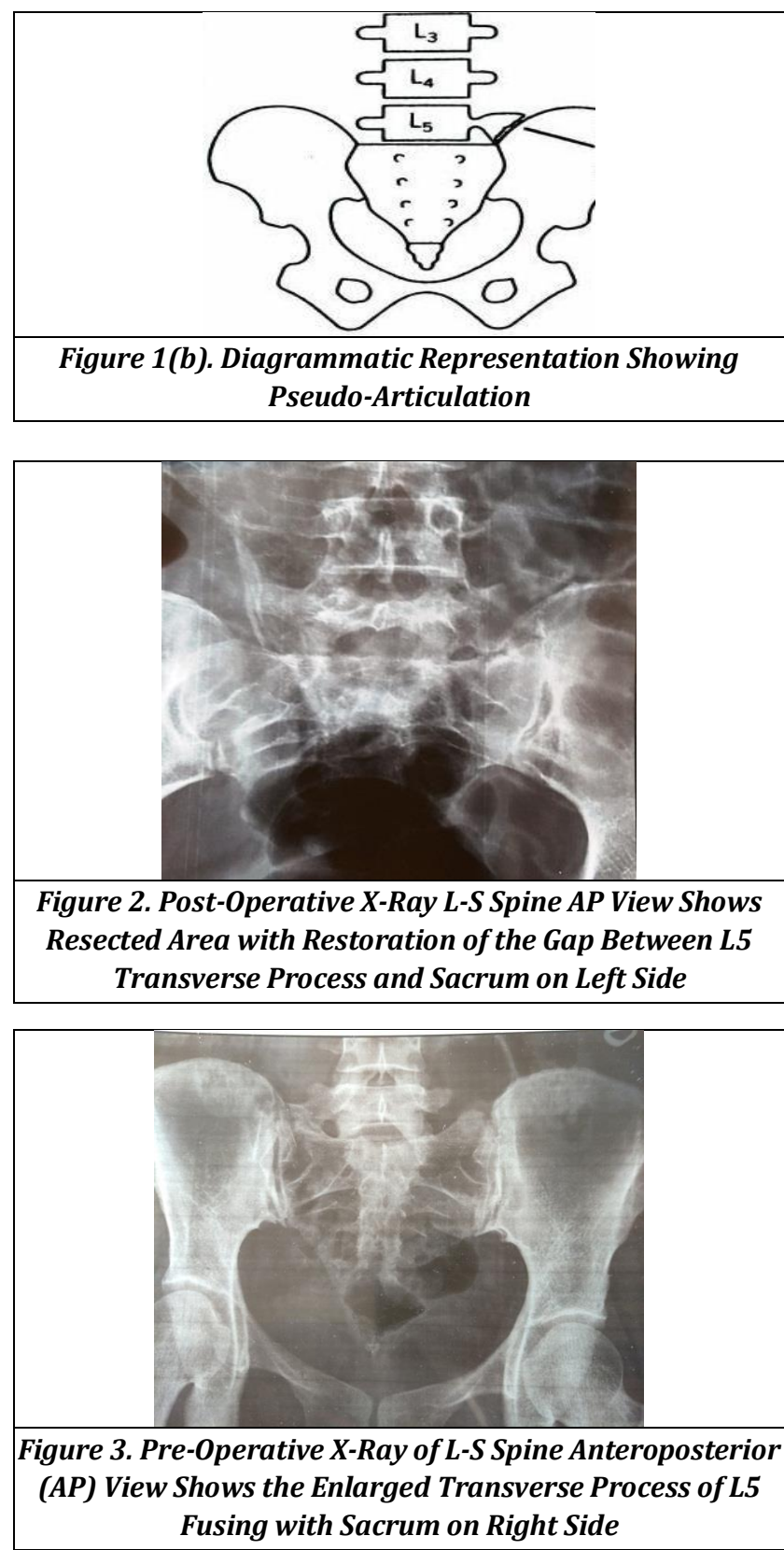


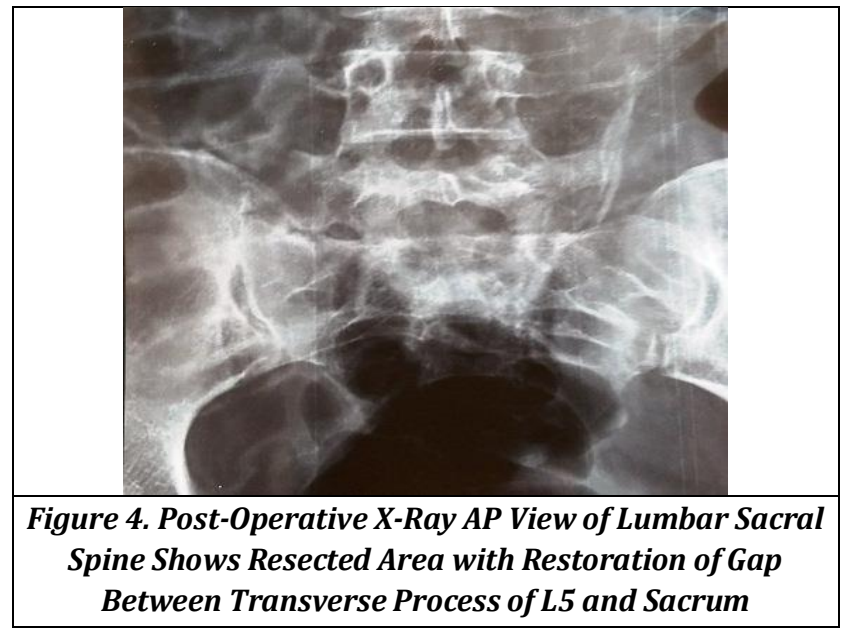

In view of chronic pain and non-relief of symptoms with medical and physiotherapy treatment, surgical excision of the pseudo-articulation of the left L5 transverse process with the sacrum was done (Figure 2). Patient became pain free after excision. The pre- and post-operative x-rays shows the restoration of normal gap between the transverse process and the sacrum.

\section{Case Report 2}

On examination shows antalgic gait, tenderness at lower lumbar region and at right posterior iliac and sacrum. Lasegue's sign/ Bragard's sign is positive on right side. Motor examination reveals EHL (Extensor halluces longus) power $3 / 5$, ankle dorsiflexion 4/5 power, reflexes normal, Babinski equivocal, no distal vascular deficit.

Plain x-ray and MRI done. Plain x-ray shows pseudo articulation of right L5 transverse process and sacrum (Figure 3). MRI scan shows disc degeneration at L4-L5 with posterolateral bulge on right side.

In view of chronic pain and non-relief of symptoms with medical and physiotherapy treatment, surgical excision is planned. Surgical excision of the pseudo-articulation of the right L5 transverse process with the sacrum was done (Figure 4). The pre and post-operative $\mathrm{x}^{-}$rays show the restoration of normal gap between the transverse process and the sacrum.

\section{DIFFERENTIAL DIAGNOSIS}

- Prolapsed intervertebral disc

- Lumbar muscular strain

- Spinal stenosis

- Vertebral discitis

\section{DISCUSSION OF MANAGEMENT}

Bertolotti's syndrome patients on examination clinically didn't reveal much information. Clinically tenderness present at the lower lumbar region severity range from mild to moderate level, particularly around the pseudo-articulation. Spine range of movements limited during acute episodes of pain and sometimes normal when there is no pain. Occasionally, there may be radicular signs. Diagnosis is based on radiological study and their correlation with clinical presentation. Plain x-ray of the lumbar-sacral spine AP view showing the presence of an enlarged transverse process of the L5 vertebra forms a joint with the sacrum or the ilium.
According to Castellvi's classification ${ }^{2}$ four types present, type I- dysplastic type transverse process (Height $>19 \mathrm{~mm}$ ),

Type II- incomplete lumbarisation/sacralisation, type IIIcomplete lumbarisation/sacralisation with complete fusion with the neighbouring sacrum and type IV- mixed. There is association between lumbosacral transitional vertebra and disc herniation and facet joint degeneration. Discs immediately above the transitional vertebra were significantly more degenerative (Disc protrusion or extrusion) compared with the disc found between the transitional vertebra and the sacrum. ${ }^{3,6}$ Luoma et al ${ }^{7}$ hypothesized that pseudo-articulation at L5-S1 restricts rotational and bending movements and the L5-S1 disc is protected from trauma. Aihara et $\mathrm{al}^{6}$ study of 70 cadavers reported that the iliolumbar ligament at the level immediately above the transitional vertebra is much thinner and weaker, especially the posterior bands of the ligament had the appearance of fascia and at the level of lumbosacral transitional vertebra it is dense fibrous connective tissue, because of this disc degeneration occur at higher vertebral levels more frequently than level L5-S1. Marks and Thulbourne $^{8}$ studied 10 patients with chronic low backache who had given a steroid and local anaesthetic infiltration for pseudo- articulation, immediate pain relief was found in 8 , but only one patient remained pain free for 2 years. Jonsson et $\mathrm{al}^{9}$ study reported relief of symptoms in 9 out of 11 patients who received an injection of local anaesthetic into the pseudo-articulation. However, these Patients underwent surgical excision of the pseudo-articulation because of recurrence of pain. Santavirta et $\mathrm{al}^{10}$ said that when the nonoperative treatment fails then resection of the abnormal transverse process can be tried. Bertolotti's syndrome ${ }^{1}$ fail to respond to non-surgical treatment that includes NSAIDs, life style activity modification and local anaesthetic and steroid injections, then surgical excision is indicated. In our two cases we identified that pain generator is the articulation between the transverse process of the L5 vertebra and the sacrum (Type II Castellvi's) based on radiographic imaging. We treated initially by conservative methods for a period of 12 months, even then no symptomatic relief. Then we excise the pseudo-articulation because of failure of conservative management. After excision patient becomes symptom free.

\section{FINAL DIAGNOSIS}

Bertolotti's Syndrome

In chronic lower back pain in younger patients one must always include Bertolotti's syndrome as a differential diagnosis. Thoroughly evaluated to identify the cause of pain. Assessment is done by proper history taking, physical examination and radiological imaging. Failure to identify it leads to misdiagnosis and sub-optimal management. Plain $\mathrm{x}$ ray of lumbar sacral spine anterior-posterior (AP) view confirms the diagnosis of Bertolotti's syndrome. Failure of non- surgical treatment in Bertolotti's syndrome surgical excision to be done to relief pain.

\section{REFERENCES}

[1] Quinlan JF, Duke D, Eustace S. Bertolotti syndrome: a cause of back pain in young people. J Bone Joint Surg (Br) 2006;88(9):1183-6. 
[2] Castellvi AE, Glodstein LA, Chan DPK. Lumbarsacral transitional vertebrae and their relationship with lumbar extradural defects. Spine (Phila Pa 1976) 1984;9(5):493-5.

[3] Vergauwen S, Parizel PM, Van Breusegem L, et al. Distribution and incidence of degenerative spine changes in patients with a lumbosacral transitional vertebra. Eur Spine J 1997;6(3):168-72.

[4] Southwood JD, Bersack SR. Anomalies of the lumbosacral junction in 550 patients without symptoms referable to the low back. AJR 1950;64:62434.

[5] Bonaiuti D, Faccenda I, Flores A. Sacralisation of the 5th lumbar vertebra and backache: what's the possible relationship? Med Lav 1997;88(3):226-36.
[6] Aihara T, Takahashi K, Ogasawara A, et al. Intervertebral disc degeneration associated with lumbosacral transitional vertebrae: a clinical and anatomical study. J Bone Joint Surg $\mathrm{Br}$ 2005;87(5):687-91.

[7] Luoma K, Vehmas T, Raininko R, et al. Lumbosacral transitional vertebra: relation to disc degeneration and low back pain. Spine 2004;29(2):200-5.

[8] Marks RC, Thulbourne T. Infiltration of anomalous articulations: Steroid and anaesthetic injections in 10 back-pain patients. Acta Orthop Scand 1991;62(2):139-41.

[9] Jonsson B, Stromqvist B, Egund N. Anomalous lumbosacral articulations and low back-pain: evaluation and treatment. Spine 1989;14(8):831-4.

[10] Santavirta S, Tallroth K, Ylinen P, et al. Surgical treatment of Bertolotti's syndrome. Follow up of 16 patients. Arch Orthop Trauma Surg 1993;112(2):82-7. 